\title{
O DIREITO HUMANO À MOBILIDADE: DOIS TEXTOS E DOIS CONTEXTOS
}

Débora Mazza ${ }^{7}$

O artigo objetiva discutir duas perspectivas de direito humano à mobilidade a partir da análise de textos escritos em diferentes contextos. São eles: a Declaração Universal de Direitos Humanos (1948) e a Diretiva de Retorno (2008). O referencial teórico adotado sugere que a mobilidade é uma prática humana milenar que tem alcançado visibilidade crescente contando com a sofisticação das tecnologias da informação, comunicação e dos transportes, globalização dos processos de produção, circulação e consumo de bens materiais e imateriais e a financeirização do capital. Entende que a migração nacional e internacional deve ser analisada considerando as múltiplas determinações do real que afetam crianças e adultos; homens e mulheres; documentados e indocumentados; países desenvolvidos e em desenvolvimento. $\mathrm{O}$ artigo sugere que a Declaração Universal de Direitos Humanos esboça uma perspectiva de direito humano à mobilidade baseada num devir de cidadania igualitária, enquanto que a Diretiva propõe normas e procedimentos comuns aos Estados de controle de entrada e condições de retorno dos migrantes não documentados, apoiados em retrações econômicas e ações xenofóbicas da sociedade civil. Aponta que países signatários da Declaração Universal dos Direitos Humanos, em 1948, são hoje, partidários da Diretiva e que esta inflexão reflete uma tendência mundial a uma perspectiva mais fechada, excludente e restritiva de governabilidade do direito humano à mobilidade.

Palavras-chave: mobilidade humana, direitos humanos, governabilidade.

1 Docente do Departamento de Ciências Sociais, Faculdade de Educação/Universidade Estadual de Campinas, Campinas, SP, Brasil. 


\section{Introdução}

A mobilidade humana é uma prática comum na história da humanidade. Entretanto, a partir de meados do século XX, tem alcançado visibilidade crescente, contando com a sofisticação das tecnologias da informação, comunicação e dos transportes, globalização dos processos de produção, circulação e consumo de bens materiais e imateriais e financeirização do capital. Os deslocamentos intra-regional e internacional - têm representado um potencial demográfico, no que diz respeito à densidade das populações nos países de origem, transito e destino; um potencial econômico, dado o impacto causado em bens, serviços, capitais e remessas financeiras; um potencial de ação social, em função das estratégias e redes que os sujeitos mobilizam nos processos migratórios; e um potencial sociocultural, devido às configurações societárias multiculturais e às diferenças e desigualdades decorrentes.

A questão que nos interessa, neste artigo, é a de atentar para duas perspectivas de interpretação e ação contemporâneas ligadas à mobilidade humana. Referimo-nos à Declaração Universal de Direitos Humanos (1948) que anuncia os valores de "igualdade, liberdade e diversidade", ampliando os espaços de luta dos movimentos sociais e tendo em vista a construção dos direitos humanos numa dimensão de cidadania universal; e a Diretiva de Retorno (2008) que defende o sistema internacional organizado em estados ou blocos regionais que exercem soberania em determinados territórios e que historicamente tratam de modo distinto os direitos dos nativos - cidadãos - e dos estrangeiros - não cidadãos ou menos cidadãos. Sugere que estes documentos sinalizam as principais questões que cercam os dilemas migratórios contemporâneos.

\section{Referenciais teóricos e metodológicos}

Pesquisas recentes ${ }^{3}$ sugerem que os fluxos migratórios devem ser analisados considerando as múltiplas determinações do real tais como: sobrevivência, regulação econômica, redes parentais, refúgios políticos, crises ecológicas e ambientais, fugas de regiões de conflito, turismo, trafico de órgãos, sexo, armas e drogas etc. A migração afeta de modo desigual e combinado, crianças, jovens, adultos e velhos; homens e mulheres; pessoas documentadas

2 A pesquisa contou com financiamento do CNPq, Processo 400185/2006-7-Edital MCT/CNPq 61/2005-Ciências Humanas/Sociais/Sociais Aplicadas.

COHEN, Robin. Globalização, migração internacional e cosmopolitismo quotidiano; DEMARTINI, Zeila de B. F.; TRUZZI, Oswaldo M.S. (orgs.). Estudos migratórios: perspectivas metodológicas; KURZ, Robert. Barbárie, migrações e guerras de ordenamento mundial; MAZZA, Débora; von SIMSON, Olga (orgs.). Mobilidade Humana e Diversidade Sócio-Cultural; PATARRA, Neide L. Governabilidade das migrações internacionais e direitos humanos: o Brasil como país de emigração; SALES, Tereza; BAENINGER, Rosana. Migrações internas e internacionais no Brasil. Panorama deste século. 
e não documentadas, países desenvolvidos e em desenvolvimento. O impacto das remessas, a redefinição de identidades nacionais, a importância das redes migratórias, as dificuldades de integração nas sociedades receptoras, a migração não documentada, a precariedade das condições de trabalho são alguns eixos em torno dos quais tem se desenvolvido o debate sobre as migrações.

Os dados quantitativos revelam a dimensão planetária do fenômeno. Segundo a International Organization for Migration o número de migrantes internacionais em todo mundo é de 232 milhões de pessoas em 2013. Uma em cada 33 pessoas é um migrante. Se juntássemos os migrantes no mundo em um território eles constituiriam o quinto país mais populoso. Eles se distribuem basicamente entre 10 principais países e os Estados Unidos representam o principal destino, hospedando $20 \%$ dos migrantes no mundo. As mulheres representam $49 \%$ destes fluxos. As remessas enviadas pelos migrantes têm aumentado exponencialmente e atingem as cifras de 440 milhões de dólares mesmo considerando os reflexos da crise econômica. Em 2010 o principal país de envio de remessas era de longe os Estados Unidos seguido da Arábia Saudita, Suíça e Rússia. Os principais países beneficiários eram Índia, China, México, Filipinas e França ${ }^{4}$. Entretanto, essas cifras devem ser relativizadas pois as fontes divergem e os dados são muitas vezes incertos devido às dinâmicas do processo de globalização e à migração irregular.

Según el Fondo das Naciones Unidas para la populación, el numero de personas viviendo en otro país distinto a su país natal habría pasado de 75 millones en 1965 a 120 millonesen 1990 y hoy estaría próximo a los 250 millones [...] se trata del $4 \%$ de la población mundial aproximadamente [...] es una proporción que poco ha variado desde la Segunda Guerra Mundial $^{5}$.

Os dados qualitativos capturam as motivações, os efeitos e os sentidos conferidos pelos migrantes a esta prática social. Sayad ${ }^{6}$ destaca a necessidade de se pensar a imigração associada à emigração, pois do ponto de vista cronológico, a imigração começa em uma sociedade quando a emigração inicia na outra. A imigração é um deslocamento de pessoas no espaço físico, entretanto, os deslocamentos não são apenas físicos, eles são qualificados nos sentidos sociais, econômicos, políticos, culturais, mediados pela língua e pela religião. Falar da imigração é falar da sociedade como um todo, numa perspectiva diacrônica (evolução no tempo) e sincrônica (concomitantes e contemporâneos). O imigrante muitas vezes é definido como uma força de trabalho provisória vinculada à expansão da produção que necessita de um estoque de mão de

\footnotetext{
4 IOM - InternationalOrganizationMigration. "Facts \& Figures. Global Estimates and Trends".

5 DOMENACH, Hervé. Movilidad espacial de la población: desafíos teóricos y metodológicos, p. 38.

6 SAYAD, Abdelmalek. A imigração ou os paradoxos da alteridade.
} 
obra. A manutenção da condição de provisoriedade possibilita que as sociedades receptoras calculem o tempo, os custos e as vantagens da imigração em decorrência das instabilidades das formas de exploração e regulação da ordem produtiva. Neste sentido, a estadia autorizada ao imigrante está vinculada ao trabalho, única razão de ser que lhe é reconhecida pela lógica econômica da sociedade receptora.

A dialética da migração confronta duas ordens de experiência vivida: a do imigrante que adentra em terra estrangeira e a do emigrante que se encontra longe de sua terra.

A migração atual não é mais limitada a determinadas levas não-simultâneas de modernização em diversos países: ela é universal; realiza-se em quase todos os lugares simultaneamente.

A migração maciça desde o final do século XX é consequência de uma nova crise socioeconômica da terceira revolução industrial, que possui um caráter global. Microeletrônica, tecnologia de informação e globalização do capital produzem, além de todas as barreiras nacionais e culturais, uma sociedade mundial, mas não positivamente como uma conquista, e sim negativamente como processo de dessecamento econômico: cada vez mais pessoas se tornam supérfluas, porque não podem mais vender sua força de trabalho. [...] em lugar de um sistema que cubra o mundo todo com trabalho assalariado e valorização, vai surgindo um capitalismo insular: no mundo inteiro, a reprodução capitalista se reduz a ilhas [...] oásis de produtividade e rentabilidade, em volta dos quais surgem desertos econômicos ${ }^{7}$.

Sob esta ótica a migração representa uma organização e uma desorganização da força de trabalho orquestrada pelos ditames do mundo produtivo.

Apesar das tentativas de restrição, controle, gestão e seleção dos imigrantes por parte dos Estados, a nível global, a migração perdura e apresenta novas formas e novos tipos. As novas formas migratórias que despontam desde os anos de 1990 podem ser denominadas de transnacionais. Elas se caracterizam por

desplazamiento de colectivos de migrantes pobres que no se proponen la sedentarización sino tan sólo, mediante largas giras o frecuentes idas y vueltas, recorrer varias naciones ricas. De esta forma, las redes y la circulación desplegadas por estos colectivos cruzan varias naciones, bien con movimientos de largas rotaciones, a modo de "giras" de ida y vuelta a su territorio, sin que ello implique sedentarización [...] Esos nuevos migrantes de aquí y de allá (en oposición a aquellos a los que se denominaba "ni de aquí ni de allá") $[\ldots]^{8}$.

7 KURZ, op. cit., p. 28.

8 TAURIUS, Alain. Pobres en migración, globalización de las economías y debilitamiento de los modelos integrados: el transnacionalismo migratorio en Europa meridional, p. 133. 
Essas migrações põem em movimento espaços de mobilidade que podem ser denominados de territórios circulatórios transnacionais e convivem com as migrações clássicas que ocupam os "lugares de trabajo agrícolas, urbanos e industriales con idas e vueltas comerciales a las ciudades, a los pueblos, al país de origen, de aquellos que desfrutan de una permanencia regularizada" ${ }^{\prime \prime}$.

Cohen ${ }^{10}$ identifica oito tipos de fluxos migratórios: trabalhadores legais, trabalhadores ilegais e indocumentados, refugiados e pessoas deslocadas, mulheres, migrantes especializados passageiros, migrantes especializados de longa duração, movimentos internos em grande escala e turismo. A globalização "vinda de cima" exercitada pela lógica do mercado de capitais e de mercadorias produz uma globalização "vinda de baixo", impulsionada pela maior pressão dos trabalhadores que veem na mobilidade uma possibilidade. Estas duas globalizações criam zonas de conflito que atritam projetos e interesses:

[...] pelo lado econômico e demográfico há o interesse por parte dos países ricos em trazer imigrantes dos países pobres, enquanto que pelo lado sociocultural há um movimento oposto de rejeição desses imigrantes, pela dificuldade de convivência com as diferenças, sobretudo as diferenças étnicas. Os movimentos de xenofobia são as expressões mais visíveis dessas dificuldades atuais de conviver com a diferença ${ }^{11}$.

É importante lembrar que não são apenas os adultos - homens e mulheres - que migram: crianças, jovens e idosos participam dos processos migratórios. Por isso é necessário compreender os sujeitos, suas posições sociais e as sociabilidades por eles configuradas em contextos de deslocamentos ${ }^{12}$.

Poderíamos continuar elencando obras e autores que têm aprofundado a problemática da mobilidade humana, entretanto, todos apontam a necessidade de se atentar para as zonas de contato entre as políticas migratórias, as políticas econômicas e as políticas sociais no trato com os migrantes, ou seja, para as perspectivas de governabilidade das migrações. Patarra sugere que

[...] a governabilidade das migrações, sua regulação e os contornos que devem assumir os acordos-bilaterais, multilaterais ou regionais para o delineamento de políticas especificas, no momento atual, vem se desenvolvendo em torno da questão dos direitos humanos, sempre evidenciando a tensão entre o conceito de soberania nacional dos estados nação e a busca do direito de livre circulação de pessoas, âncora de movimentos sociais que reivindicam para o processo humano a mesma liberdade de circulação que a globalização alcançou para os bens materiais e simbólicos ${ }^{13}$.

\footnotetext{
9 TAURIUS, op. cit., p. 135.

${ }^{10}$ COHEN, op. cit.

11 SALES, BAENINGER, op. cit., p. 40.

12 DEMARTINI, TRUZZI, op. cit.

13 PATARRA, op. cit., p. 5.
} 
A governabilidade das migrações assenta-se em processos, projetos e ações induzidos pelos principais países receptores. Neste sentido, tomamos a Declaração Universal dos Direitos Humanos e a Diretiva de Retorno como perspectivas que se estranham e orientam contemporaneamente as políticas de gestão dos fluxos de pessoas.

\section{Enfoques conflitantes}

O primeiro rascunho da Declaração foi apresentado em setembro de 1948 e mais de 50 países participaram de sua redação final. No dia 10 de dezembro de 1948, a Assembleia Geral da Organização das Nações Unidas (ONU), reunida em Paris, aprovou a Declaração Universal dos Direitos Humanos (DUDH), com a abstenção de voto de oito nações (União Soviética, Ucrânia, Bielorrússia, Tchecoslováquia, Polônia, lugoslávia, Arábia Saudita e África do Sul). Nenhuma nação, no entanto, votou contra o documento.

Neste sentido, apesar das disputas políticas, econômicas e ideológicas existentes "a Declaração espelha um momento civilizatório sem precedente, porque os sentimentos de humanidade, e superação daquilo que diminuía o gênero humano, encontra nos trinta artigos ali descritos um avanço que se consolida, em nível global"14.

O preâmbulo do documento foi escrito sob o impacto das atrocidades cometidas durante as duas Guerras Mundiais. Seu texto retoma ideais da Declaração de Independência dos Estados Unidos, de 1776, e da Revolução Francesa, contidos na Declaração dos Direitos do Homem e do Cidadão, de 1789. Tecnicamente, a Declaração é uma recomendação que a Assembleia Geral da Organização das Nações Unidas (ONU) faz a seus membros; é uma peça chave no direito internacional dos direitos humanos. O documento registra um consenso mínimo dos Estados sobre o rol dos direitos no plano universal. Embora quando da aprovação da DUDH não houvesse unanimidade entre as nações para a formulação de um tratado, a declaração estimulou a continuidade das discussões.

O Pacto Internacional sobre Direitos Civis e Políticos e o Pacto Internacional sobre Direitos Econômicos, Sociais e Culturais são frutos dessas discussões e desenvolveram pormenorizadamente o conteúdo da Declaração de 1948. Estes três instrumentos fundamentais sobre direitos humanos constituem o que se conhece hoje como a Carta Internacional de Direitos Humanos ${ }^{15}$.

A Declaração de 1948 retrata um momento histórico em que a proteção aos direitos humanos passa a se internacionalizar. Ela representa uma tentativa

\footnotetext{
${ }_{14}$ RODRIGO, Enio. As liberdades fundamentais, p. 1.

15 ALBA, Francisco. El papel de los instrumentos internacionales sobre derechos humanos en la salvaguardia de los mismos.
} 
de ruptura com um passado no qual a proteção desses direitos era uma questão meramente local, tratada no interior das constituições e leis de cada nação, e estimula os Estados a aprofundarem essa internacionalização, por meio da posterior celebração de pactos e tratados, estruturação de cortes internacionais, entre outras providências. Isso fez com que os direitos humanos, ao longo desses anos, se consolidassem como um costume internacional.

A Declaração possibilita também a inauguração de uma nova fase na história do direito internacional público porque coloca a guerra na ilegalidade e tem como ideia-guia a paz e o reconhecimento da dignidade inerente a todo ser humano e a não violência como princípio organizacional e diretivo do direito internacional dos direitos humanos.

[...] esse documento jurídico deve ser visto na sua mais ampla dimensão: a cosmopolita. (...) o adjetivo 'universal' situa a Declaração na dimensão dos cidadãos do mundo em uma hipotética República Universal que amplia e complementa a dimensão internacional ${ }^{16}$.

Lafer pontua que

[...] a afirmação jurídica dos direitos inaugura a plenitude da perspectiva dos governados. É a passagem do dever do súbito para o direito do cidadão. Daí a interconexão entre direitos humanos e a democracia. Por isso, uma parte relevante da sua tutela diz respeito às liberdades públicas e às garantias voltadas para proteger os direitos do indivíduo contra o arbítrio dos governantes e, concomitantemente, assegurar o pluralismo da sociedade ${ }^{17}$.

O ponto de partida da elaboração dos direitos humanos é o princípio republicano da igualdade e o seu corolário, o princípio da não discriminação. O desdobramento histórico desse ponto de partida norteia um processo de inclusão política, social, econômica e cultural. Além da extensão dos direitos políticos, os direitos econômicos e sociais estão direcionados para lidar com os problemas da exclusão material, promovendo a abrangência de oportunidades para a fruição dos bens que são criados numa sociedade e necessários para a dignidade da vida. Um componente da dicotomia inclusão/exclusão se traduz na percepção de que uma das funções dos direitos humanos é a de se ocupar do ser em situação vulnerável por várias razões.

No que se refere à dignidade e à capacidade humana de gozar direitos, a Declaração considera que

Todas as pessoas nascem livres e iguais em dignidade de direitos. São dotadas de razão e consciência e devem agir em relação umas às outras com espírito de fraternidade (Art. 1). Toda pessoa tem capacidade de

\footnotetext{
16 ALMEIDA, Guilherme A. A não violência e os direitos humanos, p. 1.

17 LAFER, Celso. Variações sobre um conceito, p. 1.
} 
gozar os direitos e as liberdades [...] sem distinção de qualquer espécie, seja de raça, cor, sexo, língua, religião, opinião política ou de outra natureza, origem nacional ou social, riqueza, nascimento, ou qualquer outra condição (Art. II).

Quanto à extensão dos direitos, a Declaração diz: "Toda pessoa tem direito à vida, à liberdade e à segurança pessoal" (Art. III).

No que se refere à validade dos direitos humanos na escala dos espaços sociais, a Declaração reconhece que

Toda pessoa tem o direito de ser, em todos os lugares, reconhecida como pessoa perante a lei (Art. VI). Ninguém será arbitrariamente preso, detido ou exilado (Art. IX). Ninguém será sujeito a interferências na sua vida privada [...]. Toda pessoa tem direito à proteção da lei contra tais interferências ou ataques (Art. XII).

No que se refere ao direito de emigrar a Declaração reconhece que

Toda pessoa tem direito à liberdade de locomoção e residência dentro das fronteiras de cada Estado. Toda pessoa tem o direito de deixar qualquer país, inclusive o próprio, e a este regressar (Art. XIII).

Contudo, nela não comparece o direito de imigrar, ou seja, nem a título de recomendação, ainda que moral, a Declaração sugere que os Estados devem acolher indiscriminadamente as pessoas.

No que diz respeito às condições concretas de vida humana, a Declaração afirma que toda pessoa "tem direito ao trabalho, à livre escolha de emprego condições justas e favoráveis de trabalho e à proteção contra o desemprego [...]" (cf. Art. XXIII), "direito a um padrão de vida capaz de assegurar a si e a sua família saúde e bem estar [...]" (cf. Art. XXV), "direito à instrução [...]" (cf. Art. XXVI).

No que se refere ao reconhecimento dos Estados sobre os direitos humanos, a Declaração normatiza que:

Toda pessoa tem direito a uma nacionalidade. Ninguém será arbitrariamente privado de sua nacionalidade, nem do direito de mudar de nacionalidade (Art. XV). Toda pessoa tem direito a uma ordem social e internacional em que os direitos e liberdades estabelecidos na presente Declaração possam ser plenamente realizados (Art. XVIII). - Nenhuma disposição da presente Declaração pode ser interpretada como o reconhecimento a qualquer Estado, grupo ou pessoa, do direito de exercer qualquer atividade ou praticar qualquer ato destinado à destruição de quaisquer dos direitos e liberdades aqui estabelecidos (Art. XXX).

Num mundo interdependente, unificado pela técnica e pela economia, os direitos humanos ganham uma dimensão internacional. Após os horrores do Holocausto e em decorrência do aparecimento em larga escala de deslocados no mundo ficou evidente a importância do direito "à hospitalidade universal". 
Daí a abrangente inclusão dos direitos humanos na agenda internacional, tendo como horizonte a construtiva inclusão de todos numa sociedade ${ }^{18}$.

A DUDH não se configura como uma lei, contudo é um sistema normativo internacional sobre direitos humanos. Muitos expertos a consideram como uma lei internacional consuetudinária na medida em que orienta costumes e se concretiza em pactos vinculantes de amplo alcance e de caráter geral. Fica evidente que todos os direitos reconhecidos e anunciados na Declaração se aplicam a cada um e a todos em virtude da origem comum do gênero humano. Este é um enfoque includente das normas internacionais sobre os direitos humanos.

Entretanto, o cenário internacional tem explicitado enfoques em conflito no encaminhamento da governabilidade das migrações. Os atentados terroristas ocorridos nos Estados Unidos em setembro de 2001 - além daqueles em Madri (2004) e Londres (2005) - trouxeram a imigração para o primeiro plano da política das nações desenvolvidas e aprofundaram as manifestações racistas e xenófobas contra os imigrantes.

Os atentados contra os Estados Unidos, a gravidade do fato e sua repercussão nacional e internacional levaram o governo americano a regular os fluxos migratórios por meio de super agências e mecanismos de Estado que cuidam da segurança nacional. Aprofundou-se o tratamento da migração como um problema de segurança dos nacionais, as fronteiras tornaram-se demasiadamente fiscalizadas e os imigrantes alcançaram estatutos de invasores que precisavam ser duramente vigiados. Esta abordagem tem contaminado a governabilidade das migrações entre os governos dos principais países receptores e agregada à retração das frentes de trabalho e ao desemprego estrutural tem levado a protestos envolvendo milhões de pessoas em vários países ${ }^{19}$.

A análise da questão da imigração nos Estados Unidos e em vários países ao longo dos últimos anos demonstra uma tendência a considerar a imigração como um problema de segurança nacional, tanto no sentido da preservação da ordem social, econômica e cultural, quanto na identificação dos imigrantes com o aumento da criminalidade e na estigmatização da imigração ilegal. Isto representa um retrocesso no enfoque includente proclamado na DUDH e configura uma visão restritiva, excludente e discricionária no trato com os direitos humanos.

A ideia de que as fronteiras nacionais estão mais porosas, conduz a políticas protecionistas de fechamento das divisas. A retórica das "invasões bárbaras"

18 LAFER, op. cit.

19 HARVEY, David. Os rebeldes na rua: o Partido de Wall Street encontra sua nêmesis; WALLERSTEIN, Immanuel. A esquerda mundial após 2011. 
presente nos discursos políticos ancorados em movimentos sociais xenófobos sugere que o perigo não está mais no país inimigo, podendo ser liquidado pela guerra: ele está no território nacional, ameaçando a segurança. O trabalhador imigrante pode ser confundido com um terrorista, um traficante de armas, de sexo e/ou de drogas, um invasor ${ }^{20}$.

A forma como os principais países receptores de imigrantes tem tratado o problema da imigração sinaliza para uma agenda de segurança e um padrão comum. A consolidação de "um espaço de segurança" implica em políticas restritivas, redução dos direitos dos imigrantes, autorização policial e armada de abordagem de qualquer pessoa que pareça ser estrangeira, militarização das fronteiras, limitação de liberdades e de direitos de alguns humanos e estigmatização de determinados países, gêneros, regiões, religiões e etnias.

Os Estados ricos têm imposto restrições sobre os direitos econômicos, sociais e políticos dos "não cidadãos" alegando a necessidade de uma gestão migratória aceitável para todas as partes envolvidas. Apontam dificuldades em elaborar uma política internacional de migração que articule a soberania dos Estados, o controle das fronteiras, a segurança nacional, a redução da pobreza, a proteção social e a migração.

Neste contexto, 16 de dezembro de 2008 foi aprovado pelo Parlamento Europeu e Conselho da União Europeia (UE) a Diretiva 2008/115/CE que alinha e aprofunda um conjunto de normas e procedimentos comuns nos Estados membros para o retorno dos nacionais de países terceiros em situação irregular. Leva em consideração varias resoluções em vigor no Conselho Europeu tais como: 1 - o Conselho Europeu de Tampere de 15 e 16 de outubro de 1999 que estabeleceu procedimentos coerentes em matéria de imigração e asilo, e abarca a criação de um sistema comum de asilo, uma política de imigração legal e a luta contra a imigração ilegal; 2 - o Conselho de Bruxelas de 4 e 5 de novembro de 2004 que estabeleceu uma política eficaz de expulsão e repatriação, baseado em normas comuns para que pessoas sejam retornadas humanamente, respeitando seus direitos e sua dignidade; 3 - a Decisão 2004/573/CE de 29 de abril de 2004 relativa à organização de voos conjuntos para a expulsão desde o território de dois ou mais Estados membros, de nacionais de países terceiros sobre os que tenha recaído resoluções de expulsão e confere possibilidades para que os Estados membros controlem o retorno forçoso; 4 - As "Vinte diretrizes sobre retorno forçoso" do Comitê de Ministros do Conselho Europeu de 04 de maio de 2005; 5 - o Regulamento no. 1987/2006/CE de 20 de dezembro de 2006 que prescreve sobre o estabelecimento, funcionamento e utilização do Sistema de Informação do Espaço Schengen de segunda geração (SISII); 6 - A Convenção dos

${ }^{20}$ SAID, Edward. Reflexões sobre o exílio e outros ensaios. 
Direitos da Criança das Nações Unidas de 1989 que considera que o interesse superior da criança deve ser considerado primordial pelos Estados membros ao aplicar a Diretiva; 7 - o Convenio Europeu para a Proteção dos Direitos Humanos e das Liberdades Fundamentais; 8 - a Convenção de Genebra sobre o Estatuto dos Refugiados de 28 de julho de 1951, modificada pelo Protocolo de Nova lorque de 31 de janeiro de 1967; dentre outros.

A Diretiva 2008/115/CE, além de propor o estabelecimento de normas comuns sobre retorno, expulsão, uso de medidas coercitivas, internamento e proibição de entrada, entende que para que os objetivos sejam alcançados, dada sua dimensão e efeitos, os Estados membros devem poder adotar uma metodologia comunitária segundo o princípio da subsidiariedade, excedendo, portanto, a instância dos Estados e alcançando a da União Europeia. Assim sendo,

Os Estados membros devem aplicar a presente Diretiva sem discriminação alguma em razão de sexo, raça, cor, origens étnicas ou sociais, características genéticas, língua, religião ou convicção, opiniões políticas ou qualquer outro tipo, pertencimento a uma minoria nacional, patrimônio, nascimento, incapacidade, idade ou orientação sexual ${ }^{21}$.

Ela visa promover uma política europeia mínima e comum entre os países que compõem a UE, que estimule o regresso voluntário de imigrantes ilegais e estabeleça normas de entrada, detenção, deportação e garantias processuais à imigração. Ela se aplica aos nacionais de países terceiros em situação irregular no território de um Estado membro e, em linhas gerais, prevê: 1 - a promoção do regresso voluntário de imigrantes ilegais, explicitando as condições de regresso e estabelecendo certas garantias; 2 - um período de detenção de seis meses extensível por mais doze meses dos imigrantes ilegais que se recusarem ao retorno voluntário; 3 - um período de partida voluntária que deve situar-se entre sete e trinta dias; 4 - um período de detenção do cidadão estrangeiro ilegal que não poderá exceder os seis meses podendo, em casos específicos, ser prorrogado por mais doze meses; 5 - um período de cinco anos de interdição de retorno à UE dos imigrantes ilegais que poderá ser superior se o nacional de país terceiro constituir uma ameaça grave à ordem pública, à segurança pública ou à segurança nacional; 6 - a recomendação de que a detenção dos menores e das famílias com menores deve se dar apenas como último recurso; 7 - a possibilidade do nacional de país terceiro contar com assistência jurídica, representação de um advogado e, se necessário, os serviços de um intérprete; 8 - um período entre 24 e 36 meses de transposição para a legislação nacional das orientações contidas na Diretiva.

${ }^{21}$ CONSELHO DA UNIAO EUROPEIA. Directiva 2008/115/CE, p. L 348/99. 
O texto da Diretiva 2008/115/CE retoma no Art. 2, par. 2, o Art. 13 do Código de Fronteiras Schengen e afirma o poder dos Estados membros deterem e interceptarem, por meio das autoridades competentes, os nacionais de países terceiros em situação irregular que cruzarem as fronteiras exteriores terrestres, marítimas ou aéreas de um Estado membro. Entretanto, apresenta uma ambiguidade que só se compreende a partir das instabilidades do processo produtivo e das crises econômicas que incidem sobre os países da Europa central desde as últimas décadas do século XX. Refiro-me à possibilidade dos Estados membros mudarem de posição acerca do retorno forçado de um nacional de país terceiro.

Art 6. Par. 4- Os Estados membros podem, em qualquer momento, decidir conceder a um nacional de um país terceiro que se encontra em situação irregular em seu território uma permissão de residência autônoma ou outra autorização que outorgue um direito de estadia por razões humanitárias ou de outro tipo. Neste caso não se ditara nenhuma decisão de retorno. Se já houver ditado, se revogara a decisão de retorno e se suspendera durante o período de validez da permissão de residência ou outra autorização que outorgue o direito de estadia. Par. 5- Se o nacional de país terceiro que está em situação irregular no território de um Estado membro tiver pendente um procedimento de renovação de permissão de residência ou outra autorização que outorgue o direito de estadia, o Estado membro considerará a possibilidade de abster-se de ditar uma decisão de retorno até que finalize o procedimento pendente ${ }^{22}$.

O Art. 12 evidencia que as decisões de proibição de entrada e de expulsão serão emitidas por escrito por meio de folhetos gerais informativos impressos em pelo menos 5 línguas tendo em vista facilitar a compreensão dos imigrantes ilegais que chegam em um Estado membro. Por outro lado, respeita os fundamentos de fato e de direito nacional que permitem a restrição e o sigilo de informações que visem salvaguardar a segurança nacional, a defesa, a seguridade pública para prevenção, investigação, detenção e perseguição de delitos.

O Art. 13 prescreve que o nacional de um terceiro país tem o direito efetivo de apelar contra a decisão de retorno podendo solicitar revisão desta, diante de um órgão competente composto por membros imparciais, com garantias de independência e obtendo assessoramento jurídico gratuito com assistência linguística.

O Art. 14 oferece garantias na espera do retorno e no adiamento da expulsão respeitando:

a) a manutenção da unidade familiar com os membros da família presentes em seu território nacional; b) a prestação de atenção sanitária de urgência e tratamento básico de enfermidades; c) o acesso para os menores, em

$\overline{22}$ Ibidem, p. L 348/102. 
função da duração de sua estadia, ao sistema de ensino básico; d) a consideração às necessidades especiais de pessoas vulneráveis ${ }^{23}$.

A Diretiva tem sido alvo de análises críticas que apontam que a União Europeia elaborou uma política comum de expulsão, detenção, penalização e criminalização antes mesmo de uma política geral sobre migração, admissão ou integração. Este é um marcador importante que aponta limites no direito de livre circulação de pessoas e tem impulsionado outras pecas legais que aprofundam essa tendência ${ }^{24}$.

Em 24 de setembro de 2008, foi aprovado pelo Conselho da UE o Pacto Europeu sobre a Imigração e o Asilo que desenha linhas gerais de conduta nesta matéria e segue a tendência da Diretiva 2008/115/CE de colocar a migração a serviço dos interesses econômicos e acima dos direitos humanos. Tem como pontos fundamentais:

- organizar a imigração legal tendo em conta as prioridades, as necessidades e as capacidades de acolhimento determinadas por cada Estado-Membro, e favorecer a integração; - lutar contra a imigração ilegal, nomeadamente assegurando o retorno dos estrangeiros em situação irregular ao seu país de origem ou a um país de trânsito; - reforçar a eficácia dos controles nas fronteiras; - edificar uma Europa do asilo; - criar uma parceria global com os países de origem e de trânsito, promovendo as sinergias entre as migrações e o desenvolvimento ${ }^{25}$.

O Pacto Europeu insere a gestão das migrações no quadro dos objetivos globais da UE definindo uma política comum que leve em conta o interesse coletivo e as especificidades de cada Estado-Membro admitindo que

a gestão eficaz das migrações deve [...] abarcar ao mesmo tempo a organização da migração legal e a luta contra a imigração ilegal [...] no quadro de uma parceria entre os países de origem, de transito e de destino. [...] A UE, todavia não dispõe de meios para acolher condignamente todos aqueles que nela esperam encontrar uma vida melhor [...] Por conseguinte, a organização da imigração é necessária [...] no plano do mercado de trabalho, do alojamento, dos serviços sanitários, escolares e sociais ${ }^{26}$.

Em 25 de Maio de 2009, foi aprovado pelo Conselho da UE a Diretiva 2009/50/CE que prevê condições de entrada e de residência de nacionais de países terceiros para efeitos de emprego altamente qualificado. Visa realizar progressivamente um espaço europeu de liberdade, segurança e justiça que prevê medidas em matéria de asilo, imigração e proteção dos direitos dos

\footnotetext{
${ }^{23}$ Ibidem, p. L348/105.

${ }^{24}$ ROCCA, Paolo M. della. II recepimento della Direttiva Rimpatri in Italia.

${ }^{25}$ CONSELHO DA UNIÃO EUROPÉIA. Pacto Europeu sobre a Imigração e o Asilo, p. 4.

${ }^{26}$ Ibidem, p. 2-3.
} 
nacionais de países terceiros de modo a garantir "um crescimento econômico sustentável com mais e melhores empregos e com maior coesão social, ou seja, atrair e manter mão de obra altamente qualificada de países terceiros no âmbito de uma abordagem baseada nas necessidades dos Estados membros" ${ }^{\prime 27}$.

A Diretiva 2009/50/CE reconhece

que a migração legal desempenha um papel importante no reforço da economia baseada no conhecimento na Europa e na promoção do desenvolvimento econômico [...] apresenta um plano de ação sobre migração legal, incluindo procedimentos de admissão capazes de responder prontamente às flutuações da procura de mão de obra migrante no mercado de trabalho europeu ${ }^{28}$.

Para alcançar esses objetivos, promove primeiramente dentro da União Europeia a mobilidade de trabalhadores altamente qualificados e cidadãos da União, em especial dos Estados-Membros, respeitando o princípio da preferência comunitária. Em perdurando a escassez de mão de obra altamente qualificada em determinados domínios, considerando as prioridades e as necessidades do mercado de trabalho e a capacidade de acolhimento dos Estados-Membros, favorece que nacionais de países terceiros sejam admitidos por períodos superiores a três meses, a fim de tornar a Comunidade mais atraente e manter a competitividade e o crescimento econômico.

A Diretiva estabelece no Art. $1^{\circ}$. um Cartão Azul UE como condição de entrada e residência por um período superior a três meses no território dos Estados-Membros, para efeitos de emprego altamente qualificado. O Cartão Azul UE permite ao titular e sua família residir e trabalhar em um Estado Membro.

O Art. $7^{\circ}$. prescreve que "o período normal de validade do Cartão Azul UE poderá variar entre 1 e 4 anos e quando o período coberto pelo contrato de trabalho for inferior a este período, o Cartão Azul UE será emitido ou renovado pela duração do contrato de trabalho mais três meses" 29 .

A Diretiva 2009/50/CE condiciona a concessão do Cartão Azul UE, por um dos Estados Membros, a um nacional de país terceiro desde que esse exerça uma atividade econômica assalariada em um emprego altamente qualificado sem prejuízo do princípio da preferência comunitária.

É possível sugerir que as Diretivas 2008/115/CE e 2009/50/CE ampliam o controle de entrada, prescrevem as condições de retorno forçado de migrantes não documentados, restringem e induzem a migração ao campo da governança

\footnotetext{
${ }^{27}$ CONSELHO DA UNIAO EUROPÉIA. Directiva 2009/50/CE, p. L155/17.

${ }^{28}$ Ibidem, p. L155/17.

${ }^{29}$ Ibidem, p. 155/23.
} 
econômica. Várias organizações sociais ${ }^{30}$ têm se mobilizado contra esta perspectiva de direito humano à mobilidade. Elas interpretam que as medidas nela contidas representam uma vergonha para a Europa e apontam que

[...] o tratamento securitário das migrações, a definição de critérios discriminatórios para acesso ao trabalho, o aprofundamento da criminalização da migração e a perseguição dos(as) cerca de 8 milhões de indocumentados(as) que vivem e trabalham na Europa - a quem é oferecido a expulsão como única saída - são medidas que visam consolidar uma Europa Fortaleza, da qual as associações se envergonham. Em vários Estados da UE, a recente onda de mediatização da criminalidade e as recentes declarações de responsáveis governamentais que trataram os(as) imigrantes como bodes expiatórios para o aumento da criminalidade, abrem espaço para as pressões xenófobas e racistas, e criam um ambiente propício para a desresponsabilização do Governo. Em causa está a necessidade de regularização de dezenas de milhares de imigrantes que defrontam sérias dificuldades em regularizar a sua situação. São homens e mulheres que procuraram fugir à miséria, fome, insegurança, obrigados a abandonar os seus países como consequência do aquecimento global e outras mudanças, ou que muito simplesmente tentaram mudar de vida, mas a quem não foi reconhecido o direito a procurar melhores condições de vida. Tratam-se de pessoas que não encontraram outra opção senão o recurso à clandestinidade, muitas vezes vítimas de redes sem escrúpulo. (...) Destaque-se a situação dos imigrantes sem visto de entrada, a quem a lei recusa qualquer oportunidade de legalização. Solidários(as) com a luta que se desenvolve na Europa e no mundo contra as políticas racistas e xenófobas vamos lutar pela regularização de todos imigrantes, sem exceção, cada homem/mulher (...). É uma luta emergente contra as pretensões de expulsão dos(as) imigrantes, contra a vergonha de uma Itália que estabelece testes $\mathrm{ADN}$ como instrumento de perseguição dos ciganos(as), contra as rusgas selectivas, arbitrárias e estigmatizantes, contra a criminalização dos(as) imigrantes, contra a ofensiva das políticas securitárias e racistas, alimentadas pelo tratamento jornalístico distorcido feito por alguns meios de comunicação social. Cientes de que está criado um ambiente de perseguição aos imigrantes na Europa, e rejeitando as pressões racistas e xenófobas [...] organizações de imigrantes, de direitos humanos, anti-racistas, culturais, religiosas e sindicatos, decidiram propor uma jornada de acção pela regularização dos indocumentados(as), contra a onda de xenofobia ${ }^{31}$.

${ }^{30}$ Acção Humanista Coop. e Des.; ACRP; ADECKO; AIPA - Ass. Imig. nos Açores; APODEC; Ass. Caboverdeanade Lisboa; Ass. Cubanos R.P.; Ass. de Apoio ao Estudante Africano; Ass. Lusofonia, Cult. eCidadania; Ass. Moçambique Sempre; Ass. dos Naturais do Pelundo; Ass. dos Nepaleses; Ass. orginários Togoleses; Ass. R. da Guiné-Conacri; Ass. Olho Vivo; Ass. Recr. Melhoramentos de Talude; Ballet PunguAndongo; Casa do Brasil de Lisboa; Casa Grande do Brasil; Centro P. Árabe-Puular e Cultura Islâmica; Colect. Mumia Abu-Jamal; GAIA; Khapaz - Ass. de Jovens Afrodescendentes; Núcleo do PT-Lisboa; Obra Católica Portuguesa de Migrações; Solidariedade Imigrante; SOS Racismo.

31 JORNADA DA AÇAO, Pela regularização dos(as) indocumentados(as),contra a onda xenófoba e contra o Pacto Sarkozy, p. 1-2. 


\section{Algumas considerações}

A atual fase de regulação do modelo econômico e do projeto político ocidental, do ponto de vista legal, enfrenta impasses no encaminhamento de situações ligadas ao direito humano à mobilidade. Por um lado a DUDH, carta maior que agrega diferentes povos e culturas num projeto universalista de direitos humanos com respeito ao relativismo cultural, ao multiculturalismo, a uma cidadania universal; por outro, as Diretivas que restringem a efetivação destes fundamentos e se apoiam em preconceitos xenófobos de segmentos da sociedade civil que solicitam ações restritivas por parte do Estado.

São perspectivas que se atritam. A Declaração, ao mesmo tempo em que representa um marco normativo internacional, necessita ser incorporada nos usos e costumes dos povos e nações para tornar-se uma lei internacional consuetudinária. O problema é que sua incorporação esbarra em múltiplas determinações presentes nos contextos nacionais e internacionais além de apresentar limites ao direito à migração.

O ideal de construção de uma ordem social fundada no bem comum, contido na DHDH, contrasta com os desafios e as dificuldades de sua efetivação.

[...] a Declaração de 1948 pode ser lida em linha de continuidade com outros manifestos que, em 1776, 1789, 1848, [...] sintetizaram e transformaram em bandeiras políticas a crença, nuclear da "era das revoluções", no poder da razão humana em produzir uma associação livre e sem conflito. [...] No que diz respeito à forma de relação social idealizada, esses documentos esboçam a imagem de uma ordem societária onde sentimento e razão convergem para erguer o bem e a prosperidade gerais. O retrato desse universo fraterno, isento de terror e miséria, definitiva e abstratamente incorporado à retórica do discurso dominante, contrasta de forma dramática com aquele composto pelas vivências, falas e imagens vigentes no dia a dia do homem contemporâneo. Nestas, delineiam-se alguns traços marcantes do nosso mundo real, localizáveis, pelo menos como tendências gerais, em cada especificidade histórica e conjuntural no mundo regido pela "mão invisível" do mercado. Dentre eles sobressai o aprofundamento das desigualdades sociais [...] a modernização das relações de trabalho, operada pelo desmonte de mecanismos institucionais capazes de garantir o relativo equilíbrio entre "fracos" e "fortes", traz no seu bojo o aumento irreversível do desemprego e o assombroso multiplicar-se dos números da exclusão social e da pobreza absoluta ${ }^{32}$.

A compreensão das tendências de governabilidade da migração repousa no contexto de ampliação e penetração da lógica do mercado em todos os poros da sociedade mundial. Kurz ${ }^{33}$ destaca que as migrações maciças situam-se

\footnotetext{
32 PIOZZI, Patrizia. A reinvenção da felicidade: uma breve nota sobre o cinquentenário da Declaração Universal dos Direitos Humanos, p. 2.

${ }^{33}$ KURZ, op. cit.
} 
na dependência do desenvolvimento do capitalismo global, de seus fluxos de dinheiro e mercadorias e na sua capacidade maior ou menor de aplicação da força de trabalho disponível. Elas correspondem aos diversos graus da crise e do colapso econômico em diversos países. Isto produz uma guerra de ordenamento mundial.

Sayad $^{34}$ lembra que uma das armadilhas das transações bilaterais de direitos referentes à imigração é a manutenção da ficção de que os parceiros envolvidos estão interessados e equilibrados na negociação. Na verdade, os acordos são encaminhados de forma unilateral pelo parceiro dominante e o país de emigração não pode reprovar e nem ignorar completamente o que seu interlocutor propõe. Os empregos oferecidos aos imigrantes são os suplementares: difíceis, perigosos e insalubres, mal pagos, desvalorizados e depreciados socialmente; e quanto mais dominado é o país de emigração mais forçado ele se sente a oferecer vantagens ao país receptor.

Neste contexto, os Estados economicamente mais ricos, maiores receptores de imigrantes, têm abandonado o enfoque universalista dos direitos humanos ratificado na Declaração e incorporado, nos discursos políticos e nas práticas de governos, o enfoque discrecionista expresso nas Diretivas. É importante lembrar que este processo tem contado com o apoio de movimentos sociais organizados. A condução seletiva do reconhecimento dos Estados sobre os direitos humanos justifica-se pela necessidade de governabilidade, ou seja, "a capacidade governamental de atender certas demandas ou então suprimi-las de vez" ${ }^{\prime \prime}$.

Fiori mapeando historicamente o conceito de governabilidade localiza seu surgimento no final dos anos de 1970, como conceito chave de compreensão da inflexão conservadora das teorias de politícas sociais, desenvolvimento e cidadania. Sugere que as políticas sociais que pautaram a agenda de desenvolvimento dos países capitalistas centrais nas três décadas após o fim da $2^{\text {a }}$ Guerra Mundial tinham por objetivo a construção de Estados de Bem Estar Social guiados pelo princípio de que todos deveriam ter direitos sociais a despeito das diferenças e das desigualdades de origem, renda e riqueza. Nesse sentido cabia aos Estados Nacionais, por meio de programas universais, garantir o acesso de todos aos serviços sociais de qualidade. Esse movimento associava o desenvolvimento econômico à construção da democracia tanto nos países centrais, quanto nas periferias capitalistas e, segundo essa ótica, a expansão econômica ancorava-se na construção da democracia e demandava o fortalecimento das instituições ligadas ao Estado e a ampliação crescente dos direitos humanos universais. Este é o tempo, o espaço e o espírito da Declaração.

\footnotetext{
34 SAYAD, op. cit.

${ }^{35}$ FIORI, José Luis. Governabilidade, por que e qual?, p. 2.
} 
A partir das últimas décadas do século XX, foi se desenhando nos países centrais uma nova agenda de governabilidade que implicava em "limitar vigorosamente o número de atividades submetidas ao poder regulador dos Estados" ${ }^{\prime \prime 6}$ e transferir ao setor privado a responsabilidade de oferta dos serviços sociais em decorrência de sua maior eficiência e eficácia. As políticas sociais que garantiam o acesso de todos, indiscriminadamente, aos serviços sociais passam a ser substituídas por políticas emergências e focadas a coletivos específicos. As instituições multilaterais passam a recomendar que os Estados se ocupem com as políticas sociais voltadas aos nacionais mais vulneráveis enquanto que os demais deveriam buscar no mercado os serviços que necessitavam. O critério de governabilidade abandona o horizonte da democracia e o alargamento da cidadania e passa a ser definido de forma instrumental por meio de "reformas estruturais tendo em vista a construção de instituições econômicas autônomas do ponto de vista da estabilidade das leis e da manutenção dos equilíbrios macroeconômicos"37. Existe "uma despolitização radical das relações sociais, quer por via do Estado ou de outras instituições que leva a redução da governabilidade à governança ou accontability" ${ }^{\prime 38}$.

A abordagem de governabilidade que buscava aproximar a ação do Estado calibrando os indicadores econômicos como indicadores sociais é substituída por uma abordagem que coloca a regulação do Estado a serviço das instituições econômicas tendo em vista a expansão da ordem econômica no contexto dos blocos supranacionais. A mão "invisível" do mercado, em nome da modernização das relações de trabalho, tem encurtado a mão "visível" do Estado e borrado conquistas jurídicas que perspectivavam um relativo equilíbrio entre as diferenças, as desigualdades e o desenvolvimento ${ }^{39}$. Este é o tempo, o espaço e o espírito das Diretivas que tem tangenciado a governança das migrações e o tratamento discricionário dos direitos humanos à mobilidade.

A análise das peças legais da DHDH e das Diretivas permite inferir que as políticas restritivas e seletivas de imigração e asilo se alinham às agendas turbulentas das dinâmicas econômicas contraídas que acometem os países centrais. No entanto, essas políticas não dão conta de estancar as mobilidades humanas que inscrevem no território nacional e internacional experiências de vida que transcendem a dimensão material econômica e instauram sentidos simbólicos, vínculos afetivos, redes relacionais, entre-lugares e embaralham os locais de origem, destino e circulação confundindo as Diretivas.

\footnotetext{
${ }^{36}$ Ibidem, p. 3.

37 Ibidem, p. 4.

${ }^{38}$ HELOANI, Roberto. Gestão e Organização no Capitalismo Globalizado, p. 101.

${ }^{39}$ FONSECA, Ana e FAGNANI, Eduardo (orgs.). Política social, desenvolvimento e Cidadania.
} 


\section{Referencias}

ALBA, Francisco. El papel de los instrumentos internacionales sobre derechos humanos em la salvaguardia de los mismos. REMHU, Revista Interdisciplinar da Mobilidade Humana, Brasília: CSEM, v. 16, n. 31, 2008, p. 37-62.

ALMEIDA, Guilherme A. A não violência e os direitos humanos. ComCiência. Revista Eletrônica de Jornalismo Científico, SBPC/Labjor, Unicamp, n. 106, 2009.

COHEN, Robin. Globalização, migração internacional e cosmopolitismo quotidiano. In BARRETO, Antonio (org.). Globalização e migrações. Lisboa: Imprensa de Ciências Sociais, 2005, p. 25-44.

CONSELHO DA UNIÃO EUROPEIA. Regulamento (CE) no. 1987/2006 do Parlamento Europeu e do Conselho, de 20 de Dezembro de 2006, relativo ao estabelecimento, ao funcionamento e à utilização do Sistema de Informação de Schengen de segunda geração (SIS II). In Jornal Oficial da União Europeia, p. L381/4 a L381/23, PT 28/12/2006.

CONSELHO DA UNIÃO EUROPEIA. Directiva 2008/115/ce del Parlamento Europeo y del Consejo de 16 de Diciembre de 2008 relativa a normas y procedimientos comunes en los Estados miembros para el retorno de los nacionales de terceros países en situación irregular. In Diario Oficial de la Unión Europea, p. L348/98 a 348/107, ES 24.12.2008.

CONSELHO DA UNIÃO EUROPEIA. DIRECTIVA 2009/50/CE DO CONSELHO de 25 de Maio de 2009 - relativa às condições de entrada e de residência de nacionais de países terceiros para efeitos de emprego altamente qualificado. In Jornal Oficial da União Europeia, p. L155/17 a L155/29, PT 18/06/2009.

CONSELHO DA UNIÃO EUROPEIA. Pacto Europeu sobre a Imigração e o Asílio. Doc. No. 13440/08, Bruxelas 24 de setembro de 2008, p. 1-15. Disponível em: $<$ http://register.consilium.europa.eu/pdf/pt/08/st13/st13440.pt08.pdf>. Acesso em: 20/10/2014.

DELLA ROCCA, Paolo M. II recepimento della Direttiva Rimpatri in Italia. REMHU, Revista Interdisciplinar da Mobilidade Humana, Brasília, v. 22, n. 41, Jul./Dez. 2013, p. 305-309.

DEMARTINI, Zeila de B. F.; TRUZZI, Oswaldo M.S. (orgs.). Estudos migratórios: perspectivas metodológicas. São Carlos: EDUFSCAR, 2005.

DOMENACH, Hervé. Movilidad espacial de la población: desafíos teóricos y metodológicos. In CUNHA, José Marcos P. Mobilidade espacial da população. Desafios teóricos e metodológicos para o seu estudo. Campinas: NEPO/UNICAMP, 2011, p. 33-44.

FIORI, José Luis. Governabilidade, por que e qual? Revista Teoria e Debate, n. 29, Junho/Julho/Agosto, 1995, p. 1-7.

FONSECA, Ana; FAGNANI, Eduardo (orgs.). Política social, desenvolvimento e Cidadania. Economia, distribuição de renda e mercado de trabalho. São Paulo: Fundação Perseu Abramo, 2013. 
HARVEY, David. Os rebeldes na rua: o Partido de Wall Street encontra sua nêmesis. In Occupy. Movimentos de protesto que tomaram as ruas. S.P.: Boitempo: Carta Maior, 2012, p. 57-64.

HELOANI, Roberto. Gestão e Organização no Capitalismo Globalizado: Historia da manipulação psicológica no mundo do trabalho. São Paulo: Ed. Atlas, 2003.

IOM - International Organization Migration. Facts \& Figures. Global Estimates and Trends. Disponível em: <http://www.iom.int/cms/en/sites/iom/home/aboutmigration/facts-figures-1.html> . Acesso em: 23.04.2013.

JORNADA DA AÇÃO. Pela regularização dos(as) indocumentados(as), contra a onda xenófoba e contra o Pacto Sarkozy. Comunicado de imprensa feito por Associações que convocam jornada de acção para domingo. 12 de Outubro/2008, às 15h. Disponível em: http://portaldencontros.blogspot.com.br/2008/10/jornada-deaco-contra-onda-xenfoba-e.html. Acesso em: 09.11.2014.

KURZ, Robert. Barbárie, migrações e guerras de ordenamento mundial. In SERVIÇO PASTORAL DOS MIGRANTES (org.). Travessias na desordem global: Fórum Social das Migrações. São Paulo: Paulinas, 2005, p. 25-36.

LAFER, Celso. Variações sobre um conceito. ComCiência. Revista Eletrônica de Jornalismo Científico, n. 106, 2009.

MAZZA, Débora; von SIMSON, Olga (orgs.). Mobilidade Humana e Diversidade Sócio-Cultural. Jundiaí: Paco Editorial, 2011.

ONU. Declaração Universal dos Direitos Humanos. ONU, 1948.

PATARRA, Neide L. Governabilidade das migrações internacionais e direitos humanos: o Brasil como país de emigração. In MINISTÉRIO DAS RELAÇÕES EXTERIORES/SUBSECRETARIA-GERAL DAS COMUNIDADES BRASILEIRAS NO EXTERIOR. "Brasileiros no Mundo". I Conferência sobre as Comunidades Brasileiras no Exterior. Rio de Janeiro: MRE, 2008, p. 295-322.

PIOZZI, Patrízia. A reinvenção da felicidade: uma breve nota sobre o cinqüentenário da Declaração Universal dos Direitos Humanos. Educação e Sociedade, v. 19, n. 65, Campinas, Dez/1998, p. 1-3.

RODRIGO, Enio. As liberdades fundamentais. ComCiência. Revista Eletrônica de Jornalismo Científico. SBPC/Labjor, Unicamp, n. 106, 2009.

SALES, Tereza; BAENINGER, Rosana. Migrações internas e internacionais no Brasil. Panorama deste século. Revista Travessia, Janeiro/Abril, 2000, p. 33-44.

SAID, Edward. Reflexões sobre o exílio e outros ensaios. São Paulo: Companhia das Letras, 2003.

SAYAD, Abdelmalek. A imigração ou os paradoxos da alteridade. São Paulo: USP, 1998.

TAURIUS, Alain. Pobres en migración, globalización de las economias y debilitamiento de los modelos integrados: el transnacionalismo migratorio en Europa meridional. EMPIRIA. Revista de Metodologia de Ciencias Sociales, n. 19, enero-junio, 2010, p. 133-156.

WALLERSTEIN, Immanuel. A esquerda mundial após 2011. In Occupy. Movimentos de protesto que tomaram as ruas. S.P.: Boitempo: Carta Maior, 2012, p. 73-76. 


\section{Abstract}

The human right to mobility: two texts and two contexts

This paper discusses two perspectives of human right to mobility from the analysis of texts written in different contexts. They are: The Universal Declaration of Human Rights (1948) and the Return Directive (2008). The theoretical reference adopted suggests that mobility is an ancient human practice that has achieved increased visibility based on the development of information technology, transportation and the globalization processes of production, circulation and consumption of goods, financialization and worldlization of culture. It considers that the national and international migration should be analyzed considering the multiple real determinations that affect children and adults, men and women, regular and irregular migrants, developed and developing countries. Using content analysis this article suggests that The Universal Declaration of Human Rights outlines a human right to mobility based on an equal citizenship perspective, the Return Directive proposes the criminalization of migration by the State supported by xenophobic actions from the civil society. It shows that signatory and proponent countries of The Universal Declaration of Human Rights in 1948 are today supporters of the Return Directive and that this inflection reflects a global trend towards a more closed, excluding and restrictive governance of the human right to mobility.

Keywords: human mobility, human rights, governance.

Recebido para publicação em 17/05/2014.

Aceito para publicação em 09/01/2015.

Received for publication on May, 17 $7^{\text {th }}, 2014$. Accepted for publication on January, 09 ${ }^{\text {th }}, 2015$.

ISSN impresso: 1980-8585

ISSN eletrônico: 2237-9843

www. http://dx.doi.org/10.1590/1980-85852503880004415 